\title{
Influence of Sliding-Friction Induced Strain Hardening on the Tribological Behavior of Friction Stir Processed AA2219 Alloy
}

\author{
Aashish John ${ }^{1)^{*}}$, Vimal Edachery ${ }^{1)}$, Muthumanickam Agilan ${ }^{2)}$, Anbukkarasi Rajendran ${ }^{1)}$, \\ Sribalaji Mathiyalagan ${ }^{1)}$, Hullikunte Chandrashekhariah Madhu ${ }^{1)}$ and Satish Vasu Kailas ${ }^{1)}$ \\ ${ }^{1)}$ Department of Mechanical Engineering, Indian Institute of Science, Bangalore 560012, India \\ ${ }^{2)}$ Materials and Metallurgy Group, Materials and Mechanical Entity, Vikram Sarabhai Space Centre, Trivandrum 695022, India \\ *Corresponding author: Aashish John (aashish94john@gmail.com)
}

Manuscript received 22 September 2021; accepted 13 January 2022; published 28 February 2022

\begin{abstract}
In this work, the viability of Friction Stir Processing (FSP) was explored as a potential method to enhance the tribological properties of aerospace alloy AA2219-T87. The dry sliding wear properties of FSP, and as-received AA2219 alloy in mild and severe wear regimes were studied using a vertical- interaction tribometer by varying contact pressures and sliding speeds. The results show that, FSP samples exhibited an enhanced wear resistance in the severe wear regime and can be attributed to the propensity of FSP aluminium alloy to undergo friction-induced strain hardening in-situ during dry sliding. This recurrent 'sliding-friction induced strain hardening' facilitated for an increased hardness towards the sliding-interface, thereby enhancing the wear resistance and this was confirmed through cross sectional nano-indentation studies.
\end{abstract}

\section{Keywords}

AA2219, FSP, tribology, sliding- friction induced strain hardening

\section{Introduction}

AA2219 is a precipitate hardenable alloy with $\mathrm{Cu}$ as the main alloying element [1]. It is characterised by good weldability [2], high strength to weight ratio [3] and superior cryogenic property as a result of which it is used in various applications in the aircraft industry $[4,5]$. The wide use of the material calls for the enhanced tribological properties also, which can be obtained by various surface modification, mechanical and chemical methods [6-9]. Friction stir processing (FSP) is one of the methods wherein the microstructural changes results in the improved tribological properties[10, 11]. FSP was developed based on the principle of friction stir welding and is a solid-state process. It leads to the localized modification of microstructure and helps attaining grain refinement in the processed region through dynamic recrystallisation [12-14]. The grain size can be modified further as per requirement by increasing the number of passes (repeating FSP by following the same or different axis). For instance, Ma et al. [15] reported $\sim 85 \%$ decrease in average grain size after single pass of FSP on as-cast Al-Si-Mg alloy. Few researchers have also reported similar improvement in the yield strength and ultimate tensile strength of aluminium alloy due to grain refinement and particle fragmentation [15-17]. Most notably, Karthikeyan and co-workers observed a four-fold improvement in ductility by increasing the tool rotational speed during friction stir processing [17].

The improvement in mechanical properties through FSP suggests the possibility of exploring FSP as a viable method capable of improving the wear properties of alloys. Now, for the proper understanding of tribological behaviour of a material, selection of tribological variables are equally important. Previous experimental studies had explored the possibilities of understanding abrasive and adhesive wear behaviours by changing the sliding speeds and contact pressures [18-21]. The wear behaviour of the material and its transitions like abrasion, tribo oxidation, adhesion and seizure etc. can be analysed by studying the microstructure, wear tracks, wear cross-section, and wear debris [19, 22-24]. Mihira Acharya et.al. [25] in their work has reported that the applied normal load has the highest influence on wear rate when compared to sliding velocity and distance. On analysing the possibility of FSP, it has been reported previously that the grains- refinement achieved through FSP is capable of improving wear properties [26]. These literature points out the possibility of exploring FSP surface modifications on aluminium alloy to enhance its wear properties. Also, selective determination of experimental parameters can help to understand the wear response and underlying wear mechanisms of alloys in different wear regimes. 
AA2219 being a widely used structural material in aerospace applications, understating its tribological behaviour is of great importance. Furthermore, limited literature on tribological behaviour of Friction stir processed (FSP) AA2219 puts forward the need of further study on the alloy. Hence, in the present study, an attempt has been made to understand the characteristics of AA2219 in as-received and FSP conditions. It includes understanding the influence of microstructural variations, hardness and strain hardening response on the tribological properties. For this purpose, dry sliding wear tests (with SS410 as counter surface) at different contact pressures and sliding speeds were conducted and the results were analysed.

\section{Materials and methods}

In the present investigation, AA2219 plates in T87 condition (solution heat treated + cold work with $7 \%$ thickness reduction + artificial aging) were used as base metal, hereafter referred to as the as-received (AR) material. The plates were cut out into the required dimension of $200 \mathrm{~mm} \times 100 \mathrm{~mm} \times 5 \mathrm{~mm}$. The chemical composition of AA2219 is shown in Table 1. Single pass FSP was done with the help of 3-axis friction stir welding machine designed in house (ETA Technologies Pvt. LtdBangalore, India). The process parameters were optimised after various trial experiments. The following processing parameters were used: tool rotation speed of $800 \mathrm{rpm}$, traverse speed of 300 $\mathrm{mm} / \mathrm{min}$ and tool tilt of $2^{\circ}$ [27]. The welding tool was made up of HDS (Highly Ductile Steel) material. It consists of scrolled shoulder of $25 \mathrm{~mm}$ diameter and a taper threaded pin of $6 \mathrm{~mm}$ top diameter and $4 \mathrm{~mm}$ bottom diameter. The tool pin length was $4.7 \mathrm{~mm}$ and the plunge depth $4.85 \mathrm{~mm}$. The plates were fixed with the help of fixtures and the plate was allowed to cool in air after the processing. The size of the processed region is approximately equal to the volume of the base material affected by the tapered pin during the processing.

The dry sliding wear tests were conducted with help of a vertical Interaction Pin-on-Disc (POD) tribometer in ambient conditions. In practical applications, interacting surfaces need not be always in horizontal configurations, i.e. influence from debris entrapment can be minimal. In dry sliding, vertical interaction tribometer helps to understand this type of interactions and wear mechanisms as it allows the debris to fall off during sliding. Moreover, as the interactions from third body is considerably low, it is expected that the transition from abrasive to adhesive wear (severe wear) can occur at relatively lower contact pressures. Cylindrical pins with a diameter of $4.2 \mathrm{~mm}$ were cut out from the as-received metal and from the nugget zone of the processed plate. The counter surface used was SS410 disc with an average surface roughness of $\sim$ Ra 0.6 $\mu \mathrm{m}$ and 40HRC (Hardness Rockwell C). The contact pressure of the experiments was varied from $1 \mathrm{MPa}$ to $6 \mathrm{MPa}$ and the sliding speeds were set as $0.2 \mathrm{~m} / \mathrm{s}$ and $0.8 \mathrm{~m} / \mathrm{s}$. The parameters were chosen such that the experiments can cover both abrasive (mild wear regime) and adhesive regimes (severe wear regime) of wear and the transitions in wear mechanisms. The sliding distance for the experiments were kept as a constant at $1000 \mathrm{~m}$.
The circular end of the pin was made flat for proper contact with the counter face. Prior to each experiment, pin and disc were cleaned with acetone to remove the dust particles. The radius of track used for the experiment was $35 \mathrm{~mm}$ from the centre of SS410, counter surface. To obtain constant parameters, separate discs were used for each experiment. At the start of each experiment, suitable run-in was provided so as for obtaining proper contact of the pin with the counter surface. The wear rate of the pin was recorded with the help of LVDT (Linear variable differential transformer) and that of the frictional force with the help of load cell. The wear volume is calculated by the following equation.

\section{Wear Volume $=\pi r^{2} h$}

Where $r$ is the radius of pin and $h$ is the amount of material removed calculated with the help of LVDT. The wear rate is calculated by calculating the volume of material removed per meter of material.

A sample out of the processed AA2219 plate along with asreceived material AA2219 were cut in traverse direction and was subjected to microstructural studies. The FSPed and as-received samples were polished by standard metallographic techniques, etched with Keller's reagent and was observed with optical microscope. Scanning Electron Microscope (SEM) (FEI ${ }^{\mathrm{TM}}$ Quanta 3D FEG) equipped with Electron Back Scattered Diffraction (EBSD) detector (EDAX Inc.) was used for grain size analysis. Samples were electro polishing using solution containing $70 \%$ Ethanol $+30 \% \mathrm{HNO}_{3}$ at $-20^{\circ} \mathrm{C}, 13 \mathrm{~V}$. To evaluate the grain morphology area $200 \times 200 \mu \mathrm{m}$ was scanned at the step size $0.2 \mu \mathrm{m}$. The hardness in the processed region as well as the asreceived sample was obtained from the surface with the help of Vickers hardness tests. In case of the FSP samples, the hardness was obtained from the nugget zone. Wear tested pins after the SEM and EDS surface analysis were cut, parallel to the sliding direction, and prepared for the subsurface analysis. Slicing was done from the other end of the pin, to avoid any further deformation of the worn surface. Pin cross section of the sliced samples were polished, following standard metallographic techniques and etched with Keller's reagent. The samples were observed with SEM for deformation depth analysis. Nano hardness of subsurface region was performed to quantify the strain hardening (work hardening) effect. The measurements were carried out with the help of Hysitron Nano-Indentor. The samples were polished using standard metallographic polishing till 3000 grit sized paper. Further diamond paste was used. The samples were subjected to optical profilometer and a roughness of $\sim 80 \mathrm{~nm}$ was obtained. Indentations were made with a fixed load value of $5 \mathrm{mN}$ with 10 second dwell time. Nanoindentations were performed on the subsurface, from the edge of the wear scar to middle of the cross section.

\section{Results and discussions}

3.1 Microstructure and hardness

Figures 1 (a) and (b) shows the optical images of the asreceived and friction stir processed zone of AA2219 alloy,

Table 1 Chemical composition of AA2219

\begin{tabular}{lccccccccc}
\hline Material & \multicolumn{10}{c}{ Chemical composition (\%) } \\
\hline \multirow{2}{*}{ AA2219 } & $\mathrm{Al}$ & $\mathrm{Cu}$ & $\mathrm{Mn}$ & $\mathrm{Fe}$ & $\mathrm{Zr}$ & $\mathrm{V}$ & $\mathrm{Si}$ & $\mathrm{Ti}$ & $\mathrm{Zn}$ \\
\cline { 2 - 27 } & Bal. & 6.33 & 0.34 & 0.13 & 0.12 & 0.07 & 0.06 & 0.04 & 0.02 \\
\hline
\end{tabular}



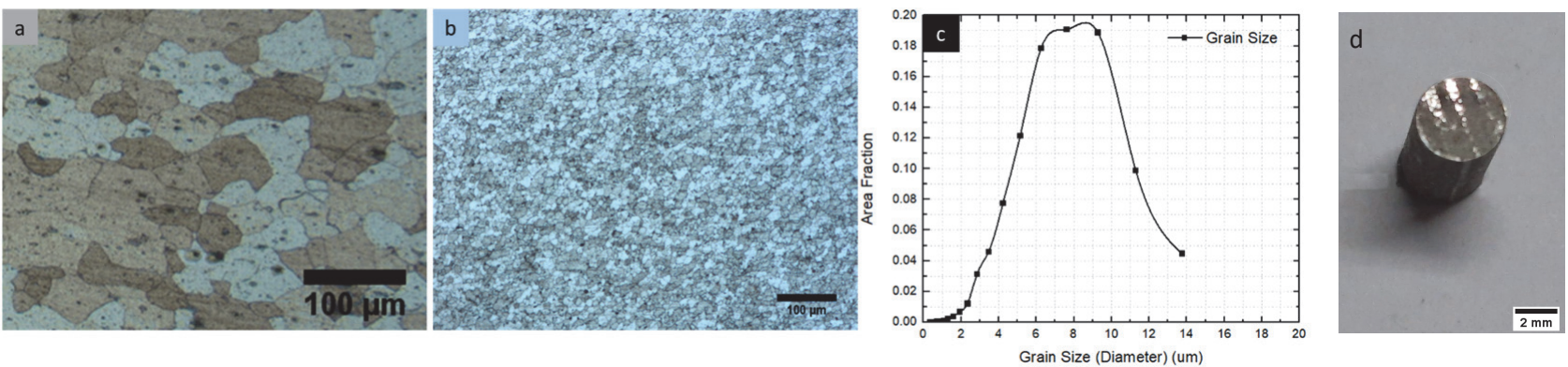

Fig. 1 Microstructure of AA2219 a) As-received b) FSP samples c) Grain Size Distribution of FSP AA2219 d) Pin sample before sliding

respectively. The as-received sample showed a coarser disorganized grain structure with an average grain size of 140 $\mu \mathrm{m}$. Stir zone in 2219 FSP sample reveals fine, recrystallized and equiaxed grains. This is due to the influence of high temperature and severe plastic deformation. The compositional analysis of these have been reported by previous reporters [28]. From the EBSD analysis it was observed that the grain diameter varied from $4 \mu \mathrm{m}$ to $12 \mu \mathrm{m}$ throughout the stir zone. The average grain diameter was measured as $7.3 \mu \mathrm{m}$. Grain refinement was observed in the processed sample. Previous researchers had reported similar refined grain structure after processing by FSP [29]. As a result of dynamic recrystallization, fine grains were observed in the FSP samples. It was earlier reported that along with the particle dissolution, fine grain structure was as a result of the low spindle speed during the friction stir processing [29]. The heat produced from the pin and shoulder and the mechanical stirring of the pin resulted in the decrease of the particle size.

The hardness values of friction stir processed and asreceived samples are given in Table 2. It was observed that the hardness of the material dropped after the friction stir processing. As-received sample hardness was $155 \mathrm{HV}$ when compared to that of FSP samples, $100 \mathrm{HV}$. The precipitates are

Table 2 Hardness of the as-received and FSP samples

\begin{tabular}{lc}
\hline \multicolumn{1}{c}{ Condition } & Hardness (HV) \\
\hline As-received AA2219 & 155 \\
\hline Friction stir processed AA2219 & 100 \\
\hline
\end{tabular}

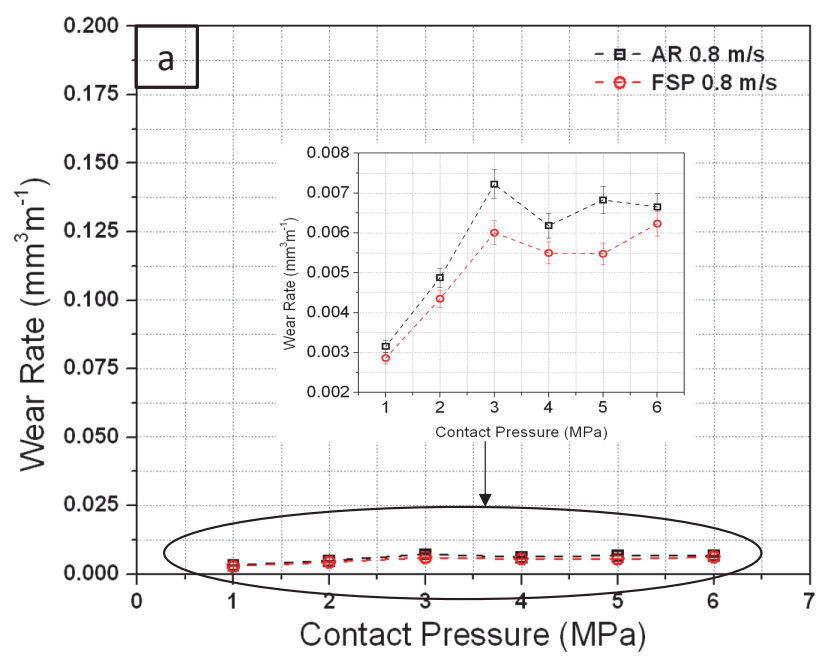

the strength imparting elements in the heat treatable alloys. In the current case AA2219 alloy is subjected to T87 treatment i.e. solutionizing, minor cold working ( $10 \%$ thickness reduction) and subsequent artificial aging, this leads to strengthening by strain hardening as well as $\theta^{\prime}$ precipitates. As the alloy is subjected to Severe Plastic Deformation the grain structure recrystalizes with low dislocation density (i.e no strain hardening). Further, during processing, temperature at the nugget in aluminium alloys are close to $450^{\circ} \mathrm{C}$ which is sufficient to dissolve strengthening precipitates in the nugget. Due to these reasons the hardness reduces after processing. The softening was caused by the coarsening and dissolution of precipitates, namely $\mathrm{Al}_{2}-\mathrm{Cu}$ [30]. Due to these reasons the hardness reduces after processing. Similar decline in the hardness at the nugget zone was observed in various alloys [30-32].

\subsection{Tribological properties}

Figures 2 (a) and (b) represents the wear rate of FSP and asreceived AA2219 samples, which were slid at the speed of 0.2 $\mathrm{m} / \mathrm{s}$ and $0.8 \mathrm{~m} / \mathrm{s}$, respectively. Wear rate was plotted against contact pressure varying from $1 \mathrm{MPa}$ to $6 \mathrm{MPa}$. The trends in the wear rate were found to be similar for both the sliding speeds, however, the FSP samples were exhibiting lower wear rate than that of as-received samples. At a lower sliding speed of $0.2 \mathrm{~m} / \mathrm{s}$, $\sim 8$ to $\sim 20 \%$ improvement in wear resistance was observed for FSP samples at various contact pressures. On considering the wear rate of samples slid at $0.8 \mathrm{~m} / \mathrm{s}$, the wear rates were having similar trends at lower contact pressures, till $4 \mathrm{MPa}$. A rapid increase in the wear rate was observed in as-received samples

Fig. 2 Wear rate of the FSP and as-received AA2219 with various contact pressures at a) $0.2 \mathrm{~m} / \mathrm{s}$ and b) $0.8 \mathrm{~m} / \mathrm{s}$

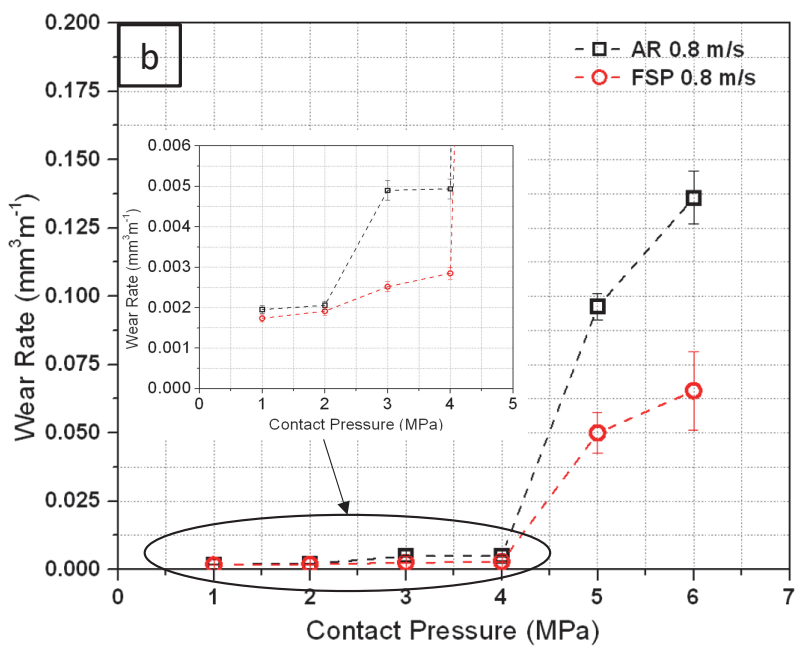


after $4 \mathrm{MPa}$ contact pressure. FSP samples exhibited $\sim 10$ to $\sim 51 \%$ improvement in wear resistance with increase in contact pressures. At $6 \mathrm{MPa}$ contact pressure, FSP samples showed a notable improvement of $51 \%$ when compared to the as-received samples. Previous literature suggests that the wear resistance of pure aluminium follows a linear relation with Grain size $e^{-1 / 2}[33]$. In line with this, the FSP AA2219 with finer grains exhibited a better wear response compared to the AA2219-T87 with coarser grains. However, as a drop in bulk hardness was also observed after FSP, the hardness dependence of wear must be explored in detail.

Figures 3 (a) and (b) show the COF (Coefficient of Friction) of the FSP and as-received samples at $0.2 \mathrm{~m} / \mathrm{s}$ and $0.8 \mathrm{~m} / \mathrm{s}$ respectively. At a lower sliding speed of $0.2 \mathrm{~m} / \mathrm{s}$, COF of FSP and as-received samples were increasing till $3 \mathrm{MPa}$ of contact pressure. After which a decline in COF was observed. Both FSP and as-received samples were showing similar friction trends, with FSP samples having an improved wear response. Similarly, for sliding speed of $0.8 \mathrm{~m} / \mathrm{s}$, both the samples were exhibiting similar trend. A decrement in $\mathrm{COF}$ was observed at $2 \mathrm{MPa}$. After which the COF was having a constant range of values. The results revealed that FSP samples were having slightly lower $\mathrm{COF}$ value than that of as-received sample. The observed change in COF can be due to the operating wear mechanism and its transitions. At contact pressure of $6 \mathrm{MPa}$ and sliding speed $0.8 \mathrm{~m} / \mathrm{s}$, an initial high COF was observed. The increase in interfacial temperature resulted in plastic deformation of the material. The plastic deformation caused an increase in the contact area of pin surface, resulting in decreased contact pressure. This resulted in a decreased COF values. The COF values were obtained after the steady state was attained. At lower speeds, the increase in contact pressure can increase abrasion and tribo-oxidation leading to increase in sliding friction, and with increase in contact pressure, the formation of finer debris can reduce friction. Hence, operating wear mechanisms can influence friction and wear. Sliding speed and contact pressure can influence the underlying wear mechanisms, hence understanding it is equally important. The operating wear mechanisms were explored by worn surface analysis using tools like SEM, EDS and Optical microscope.

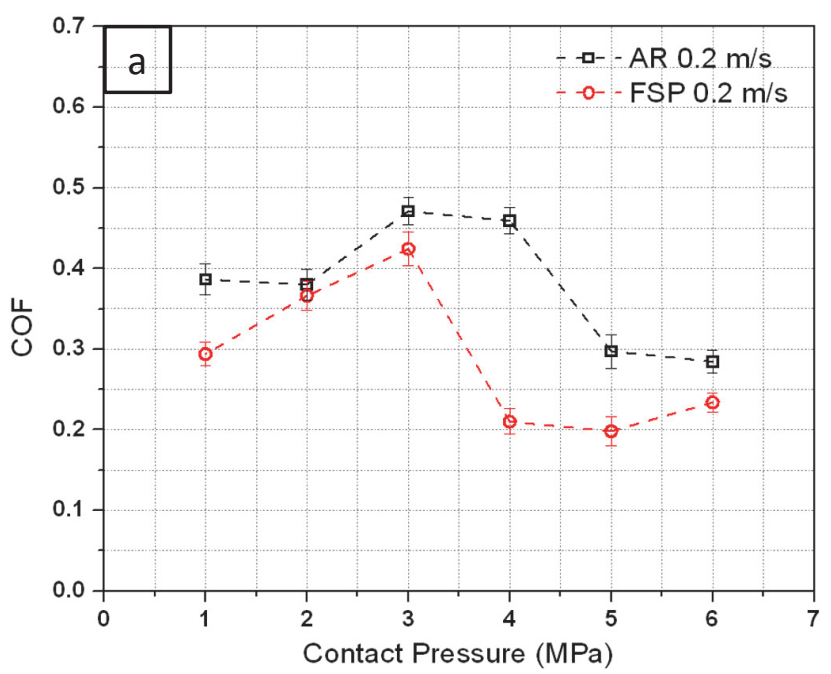

3.3 Worn surface analysis

The worn surfaces of as-received and FSP AA2219 were examined using SEM to understand the operating wear mechanisms. The SEM images of the pin surfaces after testing at a sliding speed of $0.2 \mathrm{~m} / \mathrm{s}$ are shown in Figs. 4 (a) to (d) at various contact pressure for the FSP and as-received samples. It was observed that at low sliding speed of $0.2 \mathrm{~m} / \mathrm{s}$ abrasion and tribo-oxidation were the predominant wear mechanisms. In FSP samples at contact pressures $1 \mathrm{MPa}$ and $6 \mathrm{MPa}$ the abrasion can be clearly observed. Also, during the test aluminium can react with the atmospheric oxygen and can form aluminium oxides. When the aluminium was made to slide against the counter surface, the friction will result in the increase of thermal energy. This generally can accelerate the formation of oxide layers [34-36]. Increase in contact pressure can cause an upsurge in interfacial temperature leading to increased tribo-oxidation. The formation of the oxide layer will prevent the metal-metal contact and can help reducing wear rate. However, these tribo oxide layers during sliding can get removed as debris. The white spots in images shows debris and the tribo-oxidation sites. Contact pressures and sliding speed controls the size of debris generated. More of finer debris on the worn surface with relatively lower surface-deformities can be seen at high contact pressure of $6 \mathrm{MPa}$ when compared to the surface at lower contact pressure of $1 \mathrm{MPa}$. This can reduce the friction during sliding and can be observed in Fig. 3. Similar observations were made from as-received samples also. For the as-received samples as well as FSP samples, at a sliding speed of $0.2 \mathrm{~m} / \mathrm{s}$, the tribo-oxidation sites were observed in the pin surface at all contact pressures and the predominant operating wear mechanisms were abrasion and tribo-oxidation. Similarly, the wear rate of the as-received and FSP material was observed to be almost same after $3 \mathrm{MPa}$ contact pressure. The wear transition was observed till contact pressure of $3 \mathrm{MPa}$. Beyond 3 MPa the interactions were maintained in contact phase in same wear regime and further wear transition was not observed. This has been explained with the help of SEM images of the wear scar. Thus, the wear rate after $3 \mathrm{MPa}$ was almost similar.

Figures $4(\mathrm{e})$ to $(\mathrm{h})$ show the SEM images of the wornout pin surfaces at a sliding speed of $0.8 \mathrm{~m} / \mathrm{s}$ for FSP and asreceived samples. When observing FSP samples slid at 0.8

Fig. 3 Average COF of the FSP and as-received AA2219 with various contact pressures at a) $0.2 \mathrm{~m} / \mathrm{s}$ and b) $0.8 \mathrm{~m} / \mathrm{s}$

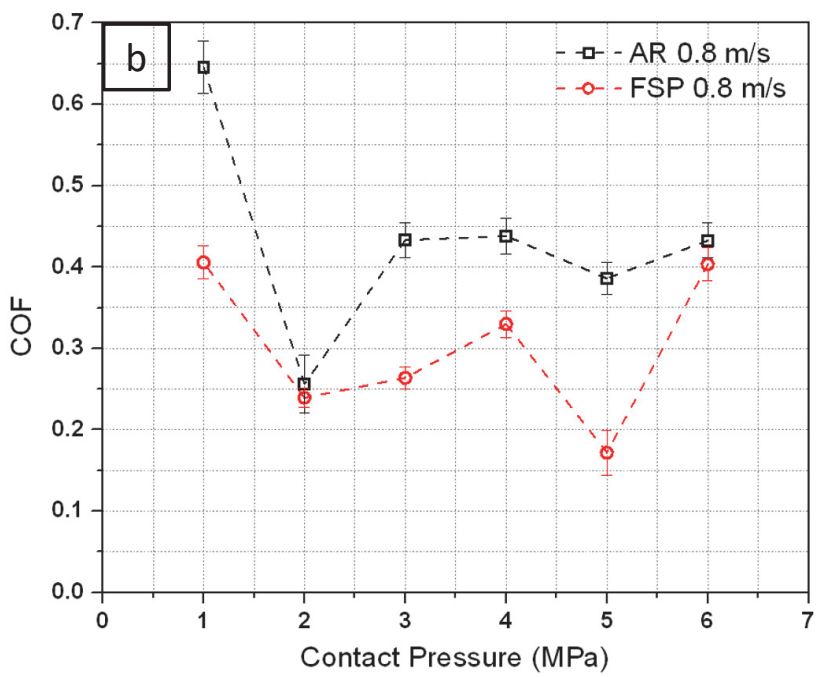


$\mathrm{m} / \mathrm{s}$, it can be seen that, at a low contact pressure of $1 \mathrm{MPa}$, adhesion of pin surface was seen in some regions however was minimal. When contact pressure was increased to $6 \mathrm{MPa}$, adhesion-plastic deformation was found to be the predominant wear mechanisms. When sliding speed and contact pressures were increased, interfacial temperature increases. At a contact pressure of $1 \mathrm{MPa}$, temperature can be relatively low that oxide formation will be more, and adhesion will be less. As the contact pressure increases the interfacial temperature decreases. The sudden rise in the wear rate after $4 \mathrm{MPa}$ points out the barrier braking point where in the adhesion starts (Fig. $2 \mathrm{~b}$ ). But as contact pressure increases to $6 \mathrm{MPa}$, adhesion was the predominant factor. At high contact pressure the flash temperature can be high enough for the pin surface to undergo plastic deformation. Tribolayers and deformation in pin shape due to plastic deformation can be clearly observed in the pin surfaces slid at higher speeds. This indicates more of metalmetal contact at higher contact pressures. For as-received samples this can result in dissolution of the precipitates locally (at interface), leading to an increased wear rate at higher contact pressures, causing large scale plastic deformation [37]. The SEM analysis confirms the deformation at the pin surface which was more than that of the counter surface. When as-received pins were analysed, oxidation with mild abrasion was observed along with plastic deformation [38]. To further confirm the inferences from SEM analysis, EDS was done on worn surfaces to analyse tribo-oxidation and possible elemental transfers from counter surface and is discussed in detail in section 3.4.

Figure 5 show stereo microscope images of the counter surfaces. From the SEM surface analysis of pin, it was inferred that as the contact pressure increases, abrasion-tribo oxidation wear mechanism changes to plastic deformation and adhesion. Abrasion marks and tribo-oxidation (darker shades) can be seen in counter surface. The aluminium transfer layers (brighter shades) can be observed on the disc surface. The transfer layers are formed due to the softening of pin due to increase in
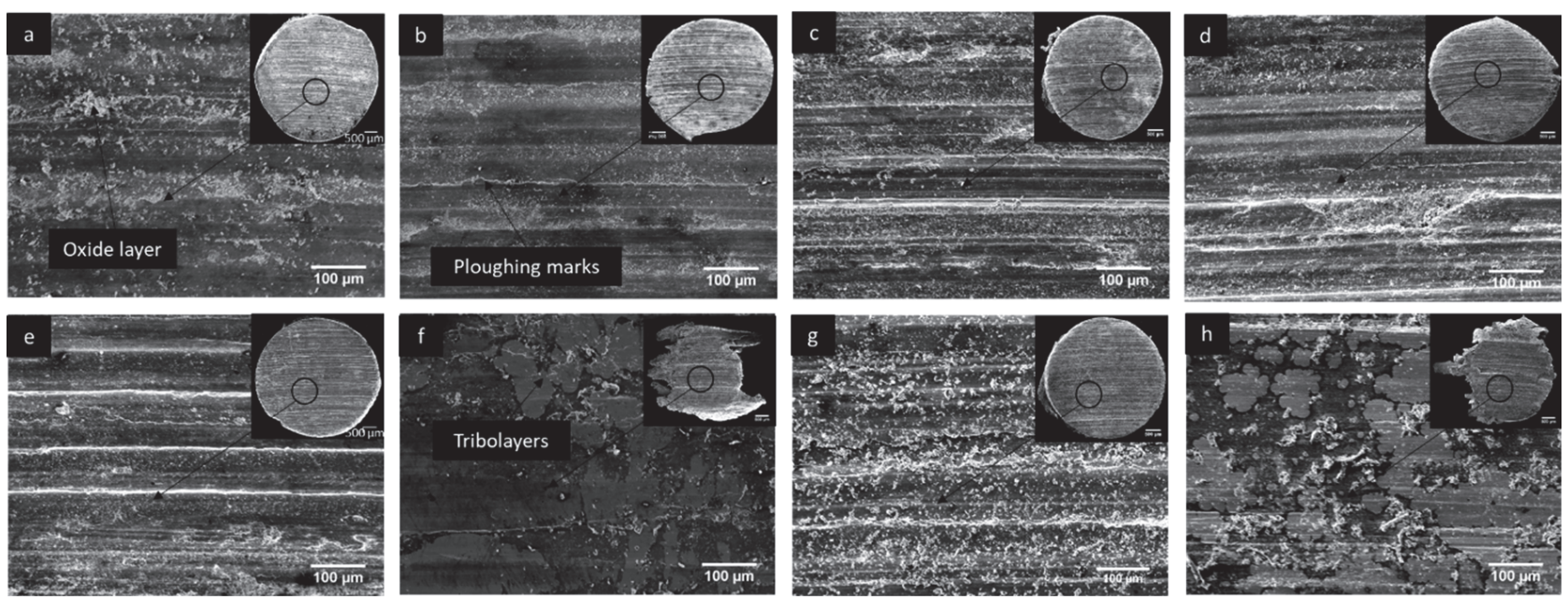

Fig. 4 SEM images of pin surfaces at $0.2 \mathrm{~m} / \mathrm{s}$ at a) FSP samples contact pressure $1 \mathrm{MPa}$, b) FSP samples contact pressure $6 \mathrm{MPa}$, c) Asreceived samples contact pressure $1 \mathrm{MPa}$ d) As-received samples contact pressure $6 \mathrm{MPa}$.

SEM images of pin surfaces at $0.8 \mathrm{~m} / \mathrm{s}$ at e) FSP sample contact pressure $1 \mathrm{MPa}, \mathrm{f}$ ) FSP sample contact pressure $6 \mathrm{MPa}$, g) Asreceived sample contact pressure $1 \mathrm{MPa}$, h) As-received sample contact pressure $6 \mathrm{MPa}$.
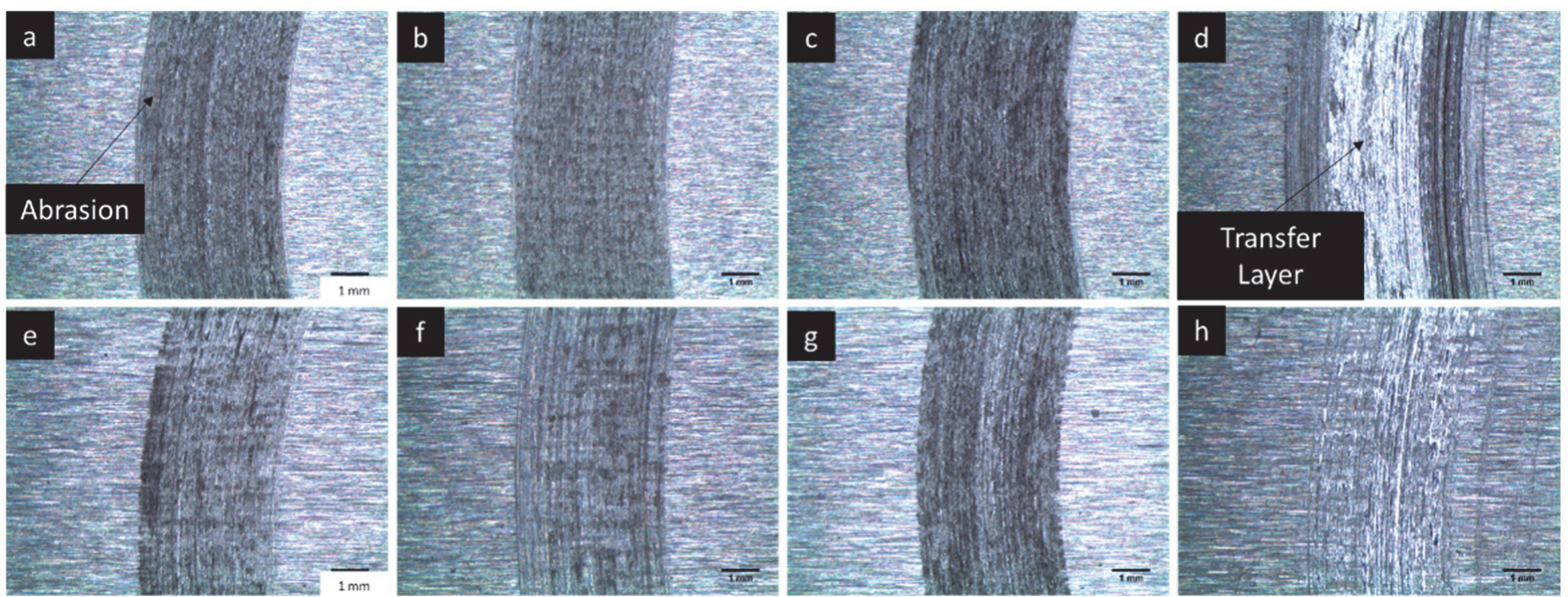

Fig. 5 Stereo microscope images of disc surfaces; (a and b): FSP contact pressure $1 \mathrm{MPa}$ at $0.2 \mathrm{~m} / \mathrm{s}$ and $0.8 \mathrm{~m} / \mathrm{s}$; (c and d): FSP contact pressure $6 \mathrm{MPa}$. at $0.2 \mathrm{~m} / \mathrm{s}$ and $0.8 \mathrm{~m} / \mathrm{s}$; (e and f): As-received material contact pressure $1 \mathrm{MPa}$ at $0.2 \mathrm{~m} / \mathrm{s}$ and $0.8 \mathrm{~m} / \mathrm{s}$; $(\mathrm{g}$ and $\mathrm{h}$ ): As-received material contact pressure $6 \mathrm{MPa}$ at $0.2 \mathrm{~m} / \mathrm{s}$ and $0.8 \mathrm{~m} / \mathrm{s}$. 
interface temperature and plastic deformation. Observations on counter surface are in accordance with the findings made from SEM analysis.

\subsection{Surface analysis using Energy Dispersive Spectroscopy}

Surface analysis using Energy Dispersive Spectroscopy was done to understand the elemental transfers that might have occurred during the sliding. Figure 6 show the EDS mapping for FSP and AR for a better visual interpretation. Figures 7 (a) and (b) shows EDS plots of FSP and as-received samples at $0.2 \mathrm{~m} / \mathrm{s}$ and $0.8 \mathrm{~m} / \mathrm{s}$ respectively. For FSP pins at $0.2 \mathrm{~m} / \mathrm{s}$, presence of $\mathrm{Fe}$ and $\mathrm{Cr}$ suggests the transfer of elements from disc surface to pin surface. The transfer of elements was seen in both the contact pressures in a similar range, suggesting transfer of elements were existing throughout the test for FSP samples. Similarly, in as-received samples, signs of abrasion and oxidation can be observed. The oxide layer formation increases with increase in contact pressure. The EDS plots also reveal the increase in transfer layers with the increase in contact pressure. At higher contact pressure and lower sliding speeds, increased $\mathrm{Fe}$ and $\mathrm{Cr}$ content in pin surface points out the wear of counter surface.
From the EDS analysis of samples slid at higher sliding speed $(0.8 \mathrm{~m} / \mathrm{s})$, it can be seen that the transfer of the elements from the counter surface to the pin surface was low. It was also evident that the transfer of the elements from the counter surface was negligibly low at higher contact pressures. Also, as the contact pressure increases it can be seen that the $\mathrm{Al}$ content was increasing. This suggests that the metal-metal contact was occurring, leading to plastic deformation and formation of transfer layers with nascent aluminium as the main element. The findings were in accordance with the conclusions drawn from SEM surface analysis.

\subsection{Subsurface studies}

Subsurface studies were done to understand the extend of deformation beneath the interacting surface of the sample. Deformation depths of the wear sample were found out with the help of the SEM images of sample cross- sections (Figs. $8 \mathrm{c}-\mathrm{f}$ ). It was observed that the deformation depth varies within a sample, hence the observed maximum and minimum deformation depth of pins at various conditions were shown in Figs. $8 \mathrm{a}$ and $\mathrm{b}$. The maximum deformation depth of the FSP pin
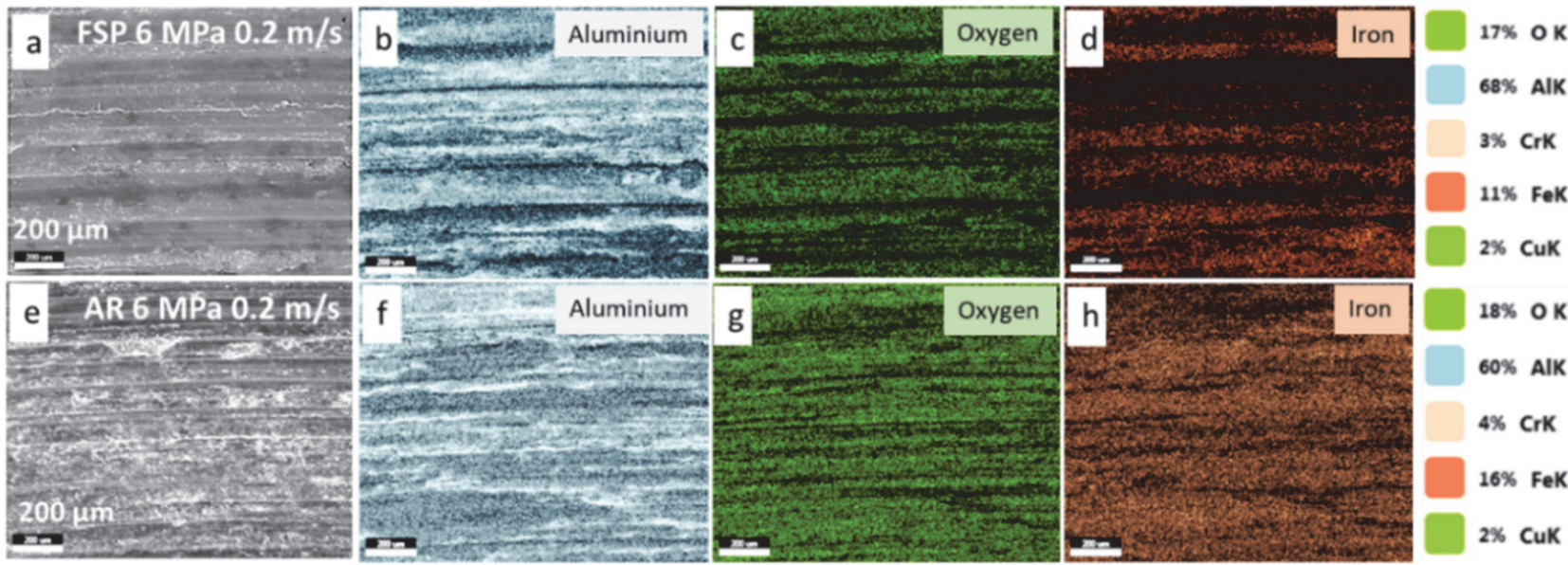

Fig. 6 EDS images of FSP and AR wear scar surface at $0.2 \mathrm{~m} / \mathrm{s}$ at $6 \mathrm{MPa}$
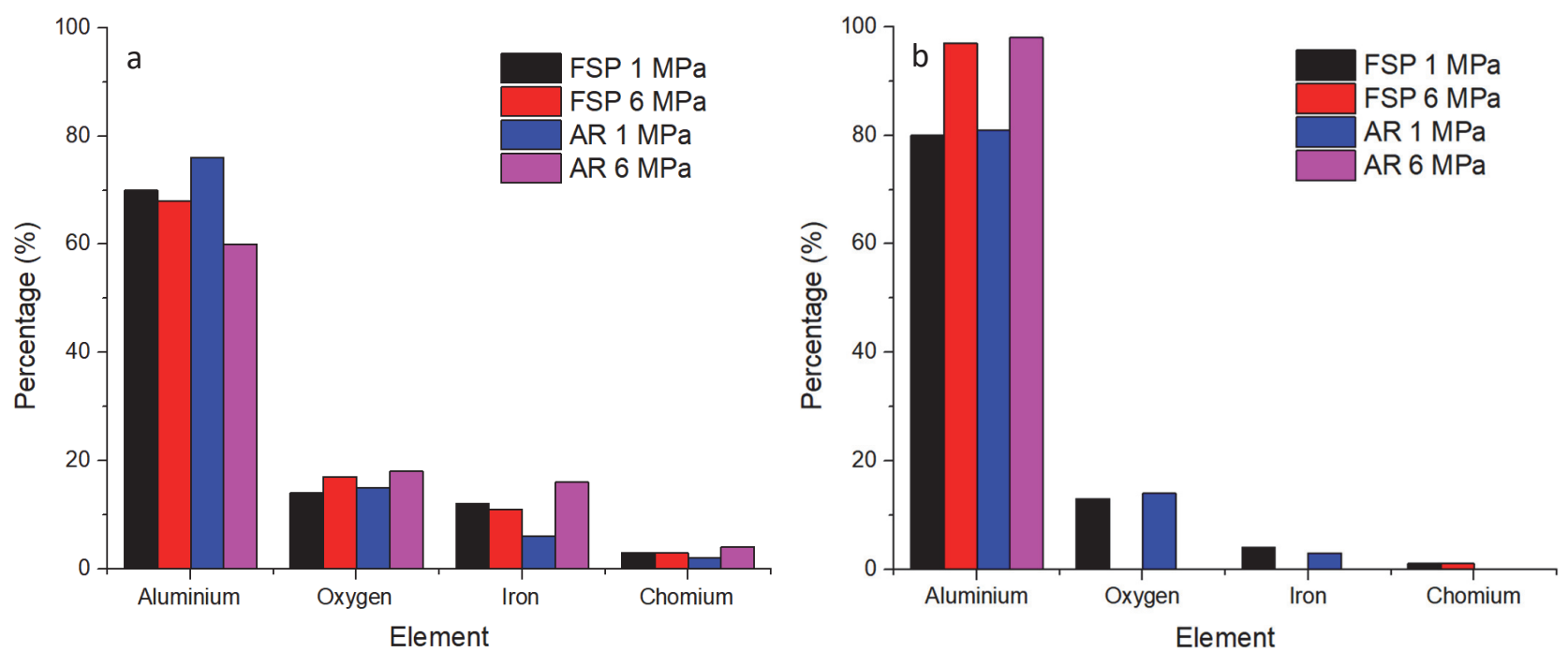

Fig. 7 EDS of FSP and as-received AA2219 pin with various contact pressures at a) $0.2 \mathrm{~m} / \mathrm{s}$ and b) $0.8 \mathrm{~m} / \mathrm{s}$ 

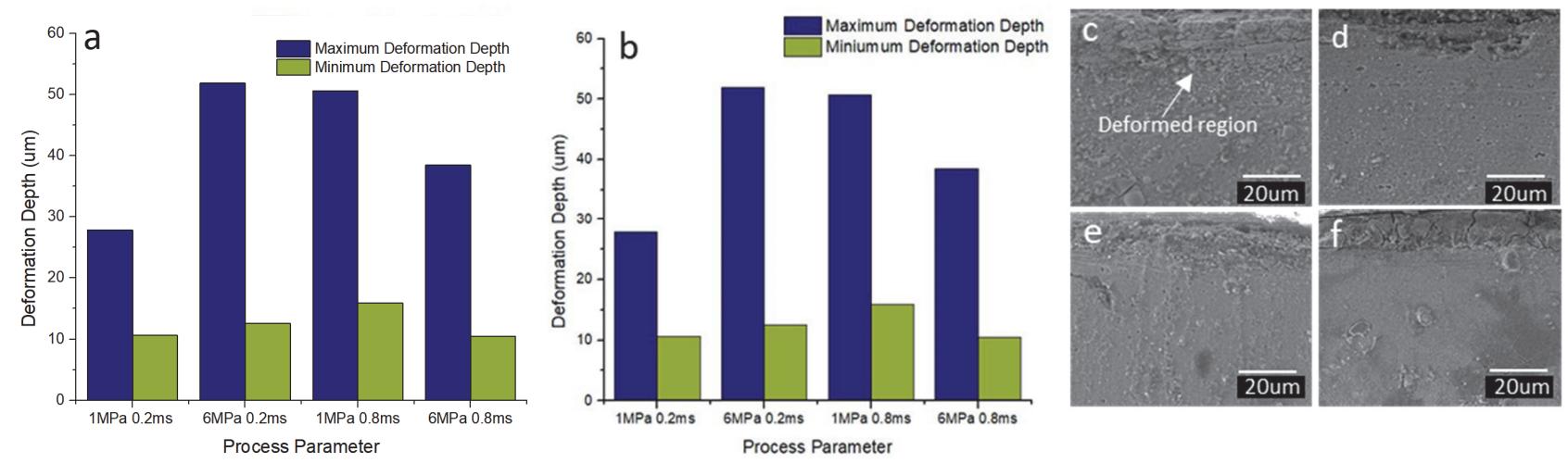

Fig. 8 Deformation depth of the FSP and as-received AA2219 with various contact pressures at a) FSP and b) As- received. (c-d) Cross section SEM of FSP at 1 and $6 \mathrm{MPa}, 0.2 \mathrm{~m} / \mathrm{s}$ (e-f) As received at $0.8 \mathrm{~m} / \mathrm{s}$

was $\sim 42 \mu \mathrm{m}$ at $6 \mathrm{MPa}$ contact pressure $(0.2 \mathrm{~m} / \mathrm{s}$ sliding speed $)$ and it varies from $42 \mu \mathrm{m}$ to $21 \mu \mathrm{m}$ within the pin. The maximum and minimum deformation depths of as-received material pins are plotted in Fig. $8 \mathrm{~b}$ and it can be seen that for $6 \mathrm{MPa}$ contact pressure $(0.2 \mathrm{~m} / \mathrm{s})$, the maximum deformation depth varies from $\sim 52 \mu \mathrm{m}$ to $\sim 27 \mu \mathrm{m}$ (Figs. $8 \mathrm{c}-\mathrm{d}$ ). Also, the difference in deformation depths of the as-received samples were more when compared to the FSP samples. At higher contact pressures and sliding speed $(0.8 \mathrm{~m} / \mathrm{s})$ the maximum deformation depth of FSP samples were found to be lesser than that of as-received samples (Figs. 8 e-f). Higher subsurface deformation can lead to increased wear rates. It was also observed that for FSP samples at contact pressure of $1 \mathrm{MPa}$, the debris seen in the deformed region consists mostly fragment fine particles. At higher sliding speeds and contact pressures, layered deformation and flaky debris were observed. Such transitions were reported earlier by previous researchers [39]. Now, the observed large difference in the deformation depth within the samples can be as a result of different operating wear mechanisms. Like, at higher speeds, the higher material removal due to adhesion and plastic deformation (which is evident from the SEM surface analysis) and can lead to flaky debris as well as large deformation variations, leading to an inferior wear response. Moreover, compared to the as-received samples, the lower deformation depth as well as the lower variations in deformation depths of the FSP samples at a higher pressure and speed, suggests the possibility of subsurface strain accumulation and hardening. Such a friction-induced strain hardening helping in achieving a lower slope in wear has been reported previously in magnesium alloy, however, was in mild wear regime [40].

\subsection{Nanoindentation studies and strain hardening response}

To explore the possibility of friction induced strain hardening which might have occurred in-situ during sliding, the hardness variations across the subsurface of pins after wear test (from the cross sectioned specimens) were studied with the help of nanoindentation. It is noteworthy to mention here that not much variations in hardness value was observed across the subsurface regime of as-received and FSP AA2219 pins after performing wear test with a lower sliding speed of $0.2 \mathrm{~m} / \mathrm{s}$ and a normal load ranging from $1 \mathrm{MPa}$ to $6 \mathrm{MPa}$. However, the subsurface of as-received and FSP pins wear tested at $0.8 \mathrm{~m} / \mathrm{s}$ with $6 \mathrm{MPa}$ load showed significant variations in hardness value, as depicted in Fig. 9 a. It is clear from Fig. 9 a that FSP sample showed the increased hardness value in the range of $\sim 2.9 \mathrm{GPa}$ at subsurface distance of $\sim 65 \mu \mathrm{m}$. An increased hardness was observed over a certain micron range. This can be attributed to the plastic deformations on the pins slid at $0.8 \mathrm{~m} / \mathrm{s}$, $6 \mathrm{MPa}$ and the deformations can be clearly observed in the SEM images (Fig. $4 \mathrm{~h}$ ). The friction induced plastic deformations during dry sliding leads to plastic strain accumulation and insitu subsurface strain hardening. This increased the subsurface hardness. It was also observed that as distance from wear surface increased, hardness dropped down to $\sim 1.8 \mathrm{GPa}$ at $\sim 160$ um. Similarly, the hardness of as-received samples was plotted with the same parameters. It was seen that, in contrast to change in hardness observed for FSP samples, as-received samples had not shown such a noticeable strain hardening response.

To understand further on the strain hardening responses shown by FSP and as-received samples, data from tensile testing was used. True stress-strain of the FSP and as-received samples are shown in Fig. 9 c. The yield strength of as received AA2219 was reduced from $382 \mathrm{MPa}$ to $195 \mathrm{MPa}$ after processing. Although grain size of the FSP alloy is considerably refined, dissolution and coarsening of strengthening precipitates. Further, the strengthening due to strain hardening is reduced due to recover any recrystallization caused by FSP thereby reducing the yield strength of the alloy [41].

Generally, strain hardening (or work hardening) can be explained as the capability of a material to harden during plastic strain or during plastic deformation. The strain hardening ability of a material can be expressed through the strain hardening exponent " $n$ ". Strain Hardening ability can be obtained using the Holloman equation which relate true stress and true strain and is given by

$$
\sigma=K \varepsilon^{n}
$$

Where $\sigma$ is true stress, $\varepsilon$ is true strain, $n$ is the strainhardening exponent and $K$ is the strength coefficient. The stressstrain data obtained from tensile tests at room temperature was used in predicting the strain-hardening behaviour by using this Holloman relation [42, 43]. The tensile testing of FSP and as-received samples were conducted with a strain rate of $2 \mathrm{~mm} / \mathrm{m}$. The strain hardening exponent for FSP sample was found out as 0.23 and that of as-received sample as 0.1 . Compared to as-received samples, FSP samples were having higher strain hardening exponent, which indicated that FSP AA2219 can strain harden more. The precipitate coarsening and grain refinement which occurs during FSP process increases the rate of strain hardening by the mechanism of dislocation movements. Similar findings were reported in earlier studies [44]. 

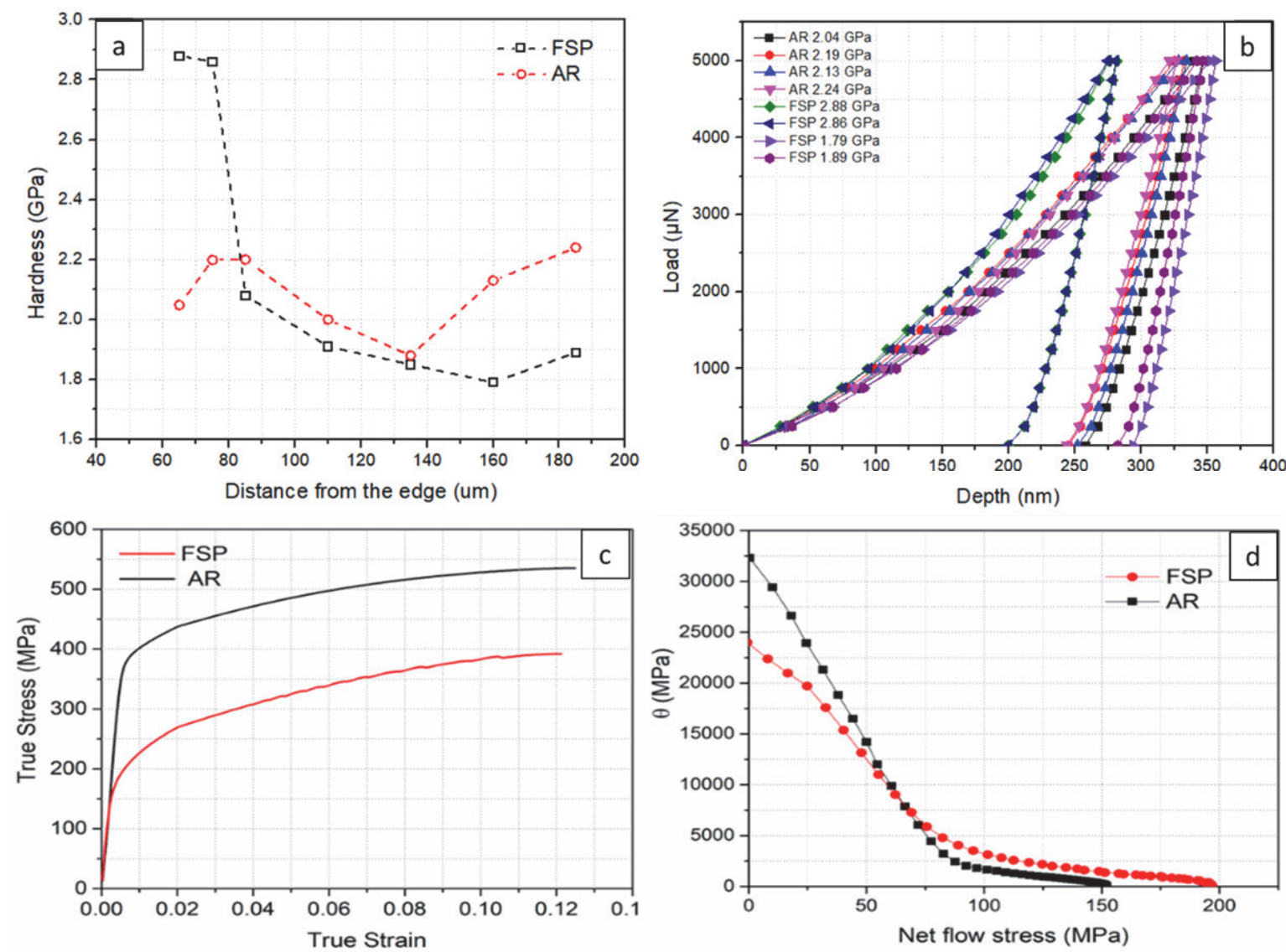

Fig. 9 a) Nanoindentation hardness of FSP and AR samples after wear test from the wear edge at contact pressure 6 MPa and sliding velocity $0.8 \mathrm{~m} / \mathrm{s} \mathrm{b}$ ) Load-depth curve for nanoindentation studies for various hardness c) True stress-strain diagram of FSP and as received AA2219 and d) strain-hardening rate $(\theta)$ vs net flow stress curves of FSP and as received AA2219

Strain hardening ability can also be indicated from KockMecking curves derived from Voces equation $\theta=\theta_{o}\left[1-\frac{\sigma}{\sigma_{s}}\right]$ where $\theta$ is strain hardening rate, $\theta_{o}$ strain hardening limit, $\sigma$ is current flow stress and os is saturation stress [45]. The KockMecking curves for the FSP and as received AA2219 is shown Fig. 9 d. The curves show typical hardening behaviour for AA2219 with stage three and four hardening. A rapid decrease in hardening rate is seen in stage three due to recovery. In stage four low and constant hardening rate is observed [46, 47]. Interestingly, FSP alloy shows extended stage 4, which indicates higher hardenability.

Apart from strain hardening exponent and Kock-Mecking curves, hardening capacity- $H_{c}$ of a material can also be figured out with the help of tensile data [42-44]. This can be obtained using the equation,

$$
H_{c}=\frac{\sigma_{U T S}-\sigma_{y}}{\sigma_{y}}=\frac{\sigma_{U T S}}{\sigma_{y}}-1
$$

Where $\sigma_{\text {UTS }}$ is the UTS, $\sigma_{y}$ is the YS of the material. The Hc of FSP samples were 0.87 when compared to as-received samples having $H_{c}$ of 0.25 . The results draw to similar conclusion as that of from the strain hardening exponent values. These findings show the higher propensity of the FSP aluminium alloy to strain harden in-situ during dry sliding.

Hence, the present study shows an enhanced wear property in a material with lower bulk hardness. However, when the scale of interpretation is changed from macro to micro, while considering the interface hardness of the materials, the results and findings are in accordance with the hardness dependence of wear. Considering the micro-tribological interactions at the interface, compared to the as-received material, the nano indentation studies shows that the FSP aluminium has a higher hardness towards the surface region, and hence, the material with higher surface hardness showed enhanced wear resistance. This increase in hardness of FSP samples towards the surface occurred in-situ during dry sliding. As explained earlier, this can be attributed to sub surface strain hardening and was observed for a few notable microns range $(\sim 10-20 \mu \mathrm{m})$. Once the initial deformed layers get removed as transfer layers and debris, the surface beneath it, which is having a higher hardness comes in to contact with the countersurface, and hence the surface with higher hardness exhibits better wear response. Moreover, in subsequent sliding interactions, the strain hardened pin sub-surface comes in contact with the initially formed Altransfer layers, thus contributing to the reduction in wear by minimizing the Al-Fe (harder counter surface) interactions. The strain hardening can also reduce the deformation depth and was observed earlier in the cross-sectional studies (Fig. 8). Generally in dry sliding, the continuous accumulation of plastic strain leads to the failure of the surface layer, i.e., once the strain reaches to failure limit [43]. In strain hardening materials, after each sliding interactions, the required strain to failure will be higher. Hence occurrence of strain hardening in-situ during sliding can reduce failure of surface layers and can significantly improve the wear resistance. These synergistic effects facilitated 
for the improvement in wear resistance of the FSP samples when compared to the as-received AA2219. The study show the potential possibilities of enhancing strain hardenability of alloys through friction stir processing for improving their tribological properties and also show that 'sliding- friction induced strain hardening' is as a factor capable of providing wear resistance.

\section{Conclusions}

Aluminium alloy AA2219-T87 (as-received material) was subjected to Friction stir processing and the tribological properties were evaluated. From the investigation following conclusions were derived:

1. Friction stir processing of AA2219-T87 resulted in the refining of grains in nugget zone. A hardness of $100 \mathrm{HV}$ was obtained at nugget zone of FSP due to the dissolution and coarsening of precipitates.

2. Wear resistance of FSP alloy was found to be superior to that of the as-received material, especially in the severe wear regime. For the FSP samples slid at higher sliding speed and contact pressure, an increased hardness was observed over a certain micron range towards the sliding- interface. This was due to the sliding-friction induced subsurface strain hardening that took place in-situ during dry sliding. This facilitated for the enhanced wear resistance of FSP AA2219 in the severe wear regime.

3. For AA2219-T87, at higher contact pressures, the plastic deformation during dry sliding and lower strain hardening response lead to an increased subsurface deformation and resulted in higher wear rates.

4. In both the FSP and as-received material, the predominant wear mechanisms observed were found to be abrasion-tribo oxidation in the mild wear regime, plastic deformation and adhesive wear in the severe wear regime (at higher contact pressure and sliding speed).

5. The study shows that interface hardness can vary in-situ during the sliding and can influence tribological response of interacting tribo-pairs. An improvement in surface hardness through sliding- friction induced strain hardening helps to enhance the wear resistance of tribo pairs experiencing higher plastic strains.

\section{References}

[1] Owolabi, G. M., Thom, M., Ajide, O. O., Kumar, N., Odeshi, A. G. and Warner, G., "Tensile Properties and Fractography of Three AA 2000 Series Aluminum Alloys Used for Aerospace Applications," Transactions of the Indian Institute of Metals, 72, 2019, 2623-2630.

[2] Manwatkar, S. K., Sunil, M., Prabhu, A., Narayana Murty, S. V. S., Joseph, R. and Ramesh Narayanan, P., "Effect of Grain Size on the Mechanical Properties of Aluminum Alloy AA2219 Parent and Weldments at Ambient and Cryogenic Temperature," Transactions of the Indian Institute of Metals, 72, 2019, 1515-1519.

[3] Elangovan, K. and Balasubramanian, V., "Influences of Tool Pin Profile and Welding Speed on the Formation of Friction Stir Processing Zone in AA2219 Aluminium Alloy," Journal of Materials Processing Technology, 200, 2008, 163-175.

[4] Sharma, V. M. J., Sree Kumar, K., Nageswara Rao, B. and Pathak, S. D., "Studies on the Work-Hardening Behavior of AA2219 under Different Aging Treatments," Metallurgical and Materials Transactions A: Physical Metallurgy and Materials Science, 40, 2009, 3186-3195.
[5] Dilip, J. J. S., Koilraj, M., Sundareswaran, V., Janaki Ram, G. D. and Koteswara Rao, S. R., "Microstructural Characterization of Dissimilar Friction Stir Welds between AA2219 and AA5083," Transactions of the Indian Institute of Metals, 63, 2010, 757-764.

[6] Nimura, K., Sugawara, T., Jibiki, T., Ito, S. and Shima, M., "Surface Modification of Aluminum Alloy to Improve Fretting Wear Properties," Tribology International, 93, 2016, 702-708.

[7] Chen, L., Liu, Z. and Shen, Q., "Enhancing Tribological Performance by Anodizing Micro-Textured Surfaces with Nano-MoS 2 Coatings Prepared on Aluminum-Silicon Alloys," Tribology International, 122, 2018, 84-95.

[8] Staia, M. H., Puchi Cabrera, E. S., Iost, A., Zairi, A., Belayer, S. and Van Gorp, A., "Tribological Response of AA 2024-T3 Aluminium Alloy Coated with a DLC Duplex Coating," Tribology International, 85, 2015, 74-87.

[9] Edachery, V., Swamybabu, V., Gurupatham, A., Paramasamy, M. and Kailas, S. V., "The Role of Surface Topography and Normal Load in the Initiation of Ratchetting-Peak Friction, Seizure, Scuffing, and Elastic Shakedown," Journal of Tribology, 144, 2021, 21704.

[10] Reddy, G. M. and Rao, K. S., "Enhancement of Wear and Corrosion Resistance of Cast A356 Aluminium Alloy Using Friction Stir Processing," Transactions of the Indian Institute of Metals, 63, 2010, 793-798.

[11] Langlade, C., Roman, A., Schlegel, D., Gete, E. and Folea, M., "Formation of a Tribologically Transformed Surface (TTS) on AISI 1045 Steel by Friction Stir Processing," Materials and Manufacturing Processes, 31, 2016, 1565-1572.

[12] Mishra, R. S. and Ma, Z. Y., "Friction Stir Welding and Processing," Materials Science and Engineering R: Reports, 50, 2005, 1-78.

[13] Joshi, S., Yuvaraj, N., Singh, R. C. and Chaudhary, R., "Microstructural and Wear Investigations of the $\mathrm{Mg} / \mathrm{B}_{4} \mathrm{C}$ Surface Composite Prepared Through Friction Stir Processing," Transactions of the Indian Institute of Metals, 73, 2020, 3007-3018.

[14] Pariyar, A., Edachery, V., John, A. and Kailas, S. V., "A Comparative Tribological Study of Inconel X750 under Surface Hardened and Non-Hardened Conditions," Surface Topography: Metrology and Properties, 9, 2021, 35020.

[15] Ma, Z. Y., Sharma, S. R. and Mishra, R. S., "Microstructural Modification of As-Cast Al-Si-Mg Alloy by Friction Stir Processing," Metallurgical and Materials Transactions A: Physical Metallurgy and Materials Science, 37, 2006, 3323-3336.

[16] Sharma, S. R., Ma, Z. Y. and Mishra, R. S., "Effect of Friction Stir Processing on Fatigue Behavior of A356 Alloy," Scripta Materialia 51, 2004, 237-241.

[17] Karthikeyan, L., Senthilkumar, V. S., Balasubramanian, V. and Natarajan, S., "Mechanical Property and Microstructural Changes during Friction Stir Processing of Cast Aluminum 2285 Alloy," Materials and Design, 30, 2009, 2237-2242.

[18] Ashok Raj, J., Pottirayil, A. and Kailas, S. V., “Dry Sliding Wear Behavior of Ti-6Al-4V Pin against SS316L Disk at Constant Contact Pressure," Journal of Tribology, 139, 2017, 021603.

[19] Pariyar, A., Edachery, V., Abhishek, B. M., Perugu, C. S., Rajneesh, H. and Kailas, S. V., "In-Situ Interfacial Growth of TiAl Intermetallic and Its Influence on Microparticle Dislodgement during Abrasive Wear of Al/Ti6Al4V Composite," Materials Today Communications, 24, 2020, 101123.

[20] Madhu, H. C., Edachery, V., Lijesh, K. P., Perugu, C. S. and Kailas, S. V., "Fabrication of Wear-Resistant $\mathrm{Ti}_{3} \mathrm{AlC}_{2} / \mathrm{Al}_{3} \mathrm{Ti}$ Hybrid Aluminum Composites by Friction Stir Processing," Metallurgical and Materials Transactions A: Physical Metallurgy and Materials Science, 51, 2020, 4086-4099.

[21] Peng, J., Wang, B., Jin, X., Xu, Z., Liu, J., Cai, Z., Luo, Z. and Zhu, M., "Effect of Contact Pressure on Torsional Fretting Fatigue Damage 
Evolution of a 7075 Aluminum Alloy," Tribology International, 137, 2019, 1-10.

[22] Ghazali, M. J., Rainforth, W. M. and Jones, H., “The Wear of Wrought Aluminium Alloys under Dry Sliding Conditions," Tribology International, 40, 2007, 160-169.

[23] Lu, J., Song, Y., Hua, L., Zhou, P. and Xie, G., “Effect of Temperature on Friction and Galling Behavior of 7075 Aluminum Alloy Sheet Based on Ball-on-Plate Sliding Test," Tribology International, 140, 2019, 105872

[24] Edachery, V., John, A., Rajendran, A., Srinivasappa, V., Mathiyalagan, S., Kumar, S. and Kailas, S. V., “Enhancing Tribological Properties of Inconel X-750 Superalloy Through Surface Topography Modification by Shot Blasting," Materials Performance and Characterization, 10, 2021, 322-332.

[25] Acharya, M. and Mandal, A., "Effect of Semi-Solid Heat Treatment on the Microstructure and Dry Sliding Wear Behavior of Al-20Si Alloy at Optimized Parametric Conditions," Metals and Materials International, 27, 2021, 1578-1586.

[26] Thapliyal, S. and Dwivedi, D. K., "Study of the Effect of Friction Stir Processing of the Sliding Wear Behavior of Cast NiAl Bronze: A Statistical Analysis," Tribology International, 97, 2016, 124-135.

[27] Dixit, S., Madhu, H. C., Kailas, S. V. and Chattopadhyay, K., “Role of Insert Material on Process Loads during FSW," International Journal of Advanced Manufacturing Technology, 91, 2017, 3427-3435.

[28] Surekha, K., Murty, B. S. and Rao, K. P., “Microstructural Characterization and Corrosion Behavior of Multipass Friction Stir Processed AA2219 Aluminium Alloy," Surface and Coatings Technology, 202, 2008, 4057-4068.

[29] Hassan, K. A. A., Norman, A. F., Price, D. A. and Prangnell, P. B., "Stability of Nugget Zone Grain Structures in High Strength Al-Alloy Friction Stir Welds during Solution Treatment," Acta Materialia, 51, 2003, 1923-1936.

[30] Srinivasan, P. B., Arora, K. S., Dietzel, W., Pandey, S. and Schaper, M. K., "Characterisation of Microstructure, Mechanical Properties and Corrosion Behaviour of an AA2219 Friction Stir Weldment," Journal of Alloys and Compounds, 492, 2010, 631-637.

[31] Hulbert, D., Fuller, C., Mahoney, M. and London, B., "The Mechanical and Thick Section Bending Behavior of Friction Stir Processed Aluminum Plate," Scripta Materialia, 57, 2007, 269-272.

[32] Liu, G., Murr, L. E., Niou, C. S., McClure, J. C. and Vega, F. R., "Microstructural Aspects of the Friction-Stir Welding of 6061-T6 Aluminum," Scripta Materialia, 37, 1997, 355-361.

[33] Prasada Rao, A. K., Das, K., Murty, B. S. and Chakraborty, M., “Effect of Grain Refinement on Wear Properties of Al and Al-7Si Alloy," Wear, 257, 2004, 148-153.

[34] Razavizadeh, K. and Eyre, T. S., “Oxidative Wear of Aluminium Alloys," Wear, 79, 1982, 325-333.

[35] Huang, S. J., Abbas, A. and Ballóková, B., “Effect of CNT on
Microstructure, Dry Sliding Wear and Compressive Mechanical Properties of AZ61 Magnesium Alloy," Journal of Materials Research and Technology, 8, 2019, 4273-4286.

[36] Abbas, A., Huang, S. J., Ballóková, B. and Sülleiová, K., “Tribological Effects of Carbon Nanotubes on Magnesium Alloy AZ31 and Analyzing Aging Effects on CNTs/AZ31 Composites Fabricated by Stir Casting Process," Tribology International, 142, 2020, 105982.

[37] Basavakumar, K. G., Mukunda, P. G. and Chakraborty, M., "Influence of Melt Treatments on Sliding Wear Behavior of Al-7Si and Al-7Si-2.5Cu Cast Alloys," Journal of Materials Science, 42, 2007, 7882-7893.

[38] Ballóková, B., Falat, L., Puchý, V., Molčanová, Z., Besterci, M., Džunda, R., Abbas, A. and Huang, S. J., "The Influence of Laser Surface Remelting on the Tribological Behavior of the ECAP-Processed AZ61 Mg Alloy and AZ61- $\mathrm{Al}_{2} \mathrm{O}_{3}$ Metal Matrix Composite," Materials, 13, 2020, 2688.

[39] Jung, J., Oak, J. J., Kim, Y. H., Cho, Y. J. and Park, Y. H., “Wear Behaviors of Pure Aluminum and Extruded Aluminum Alloy (AA2024-T4) under Variable Vertical Loads and Linear Speeds," Metals and Materials International, 23, 2017, 1097-1105.

[40] Liang, C., Han, X., Su, T. F., Lv, X. X. and An, J., "Roles of FrictionInduced Strain Hardening and Recrystallization in Dry Sliding Wear of AZ31 Magnesium Alloy," Transactions of the Indian Institute of Metals, 68, 2015, 89-98.

[41] Kumar, N., Mishra, R. S., Huskamp, C. S. and Sankaran, K. K., "The Effect of Friction Stir Processing on the Microstructure and Mechanical Properties of Equal Channel Angular Pressed 5052Al Alloy Sheet," Journal of Materials Science, 46, 2011, 5527-5533.

[42] Xu, W. F., Liu, J. H., Chen, D. L., Luan, G. H. and Yao, J. S., "Improvements of Strength and Ductility in Aluminum Alloy Joints Via Rapid Cooling during Friction Stir Welding," Materials Science and Engineering A, 548, 2012, 89-98.

[43] Ni, D. R., Chen, D. L., Wang, D., Xiao, B. L. and Ma, Z. Y., “Tensile Properties and Strain-Hardening Behaviour of Friction Stir Welded SiCp/AA2009 Composite Joints," Materials Science and Engineering A, 608, 2014, 1-10.

[44] Xu, W., Liu, J., Chen, D., Luan, G. and Yao, J., "Tensile Properties and Strain Hardening Behavior of a Friction Stir Welded AA2219 Al Alloy," Advanced Materials Research, 291-294, 2011, 833-840.

[45] Kocks, U. F., "Laws for Work-Hardening and Low-Temperature Creep," Journal of Engineering Materials and Technology, 98, 1976, $76-85$.

[46] Mock, F., "Laws for Work-Hardening and Low Temperature Creep," Journal of Engineering Materials and Technology, 98, 1, 1976, 76-85.

[47] Kuhlmann-Wilsdorf, D. and Hansen, N., "Theory of WorkHardening Applied to Stages III and IV," Metallurgical Transactions A, 20, 1989, 2393-2397.

This paper is licensed under the Creative Commons Attribution-NonCommercial-NoDerivatives 4.0 International (CC BYNC-ND 4.0) License. This allows users to copy and distribute the paper, only upon conditions that (i) users do not copy or distribute such paper for commercial purposes, (ii) users do not change, modify or edit such paper in any way, (iii) users give appropriate credit (with a link to the formal publication through the relevant DOI (Digital Object Identifier)) and provide a link to this license, and (iv) users acknowledge and agree that users and their use of such paper are not connected with, or sponsored, endorsed, or granted official status by the Licensor (i.e. Japanese Society of Tribologists). To view this license, go to https://creativecommons.org/licenses/by-nc-nd/4.0/. Be noted that the third-party materials in this article are not included in the Creative Commons license, if indicated on the material's credit line. The users must obtain the permission of the copyright holder and use the third-party materials in accordance with the rule specified by the copyright holder. 